University of Texas at El Paso

ScholarWorks@UTEP

$5-2006$

\title{
Helping Students to Become Researchers: What We Can Gain from Russian Experience
}

Vladik Kreinovich

The University of Texas at El Paso, vladik@utep.edu

Ann Q. Gates

The University of Texas at El Paso, agates@utep.edu

Olga Kosheleva

The University of Texas at El Paso, olgak@utep.edu

Follow this and additional works at: https://scholarworks.utep.edu/cs_techrep

Part of the Computer Engineering Commons

Comments:

Updated version UTEP-CS-06-08b.

Shorter version published in the Proceedings of the 2006 International Sun Conference on Teaching and Learning, El Paso, Texas, March 3-4, 2006, http://sunconference.utep.edu/ SunHome/2006/proceedings2006.html; final version published in the Proceedings of the 36th ASEE/IEEE Frontiers in Education Conference FIE'2006, San Diego, California, October 28-31, 2006, pp. M3G-26 - M3G-31.

\section{Recommended Citation}

Kreinovich, Vladik; Gates, Ann Q.; and Kosheleva, Olga, "Helping Students to Become Researchers: What We Can Gain from Russian Experience" (2006). Departmental Technical Reports (CS). 154.

https://scholarworks.utep.edu/cs_techrep/154

This Article is brought to you for free and open access by the Computer Science at ScholarWorks@UTEP. It has been accepted for inclusion in Departmental Technical Reports (CS) by an authorized administrator of ScholarWorks@UTEP. For more information, please contact Iweber@utep.edu. 


\title{
Helping Students to Become Researchers: What We Can Gain from Russian Experience
}

\author{
Vladik Kreinovich, Ann Gates, and Olga Kosheleva \\ Departments of Computer Science and Teacher Education, \\ University of Texas at El Paso, El Paso, TX 79968, \\ \{vladik,agates,olgak\}@utep.edu
}

\begin{abstract}
The fact that many internationally renowned scientists have been educated in the former Soviet Union shows that many features of its education system are effective. In this session, we briefly describe useful features. Some of these features have been successfully implemented (with appropriate adjustments) in affinity research groups at the Department of Computer Science of the University of Texas at El Paso (UTEP).
\end{abstract}

Index Terms - Russian experience, seminars, clusters, affinity research groups

\section{INTRODUCTION}

Many internationally renowned scientists have been educated in the former Soviet Union, especially in mathematics, physics, and computer science. This fact leads to a reasonable conclusion that many features of the Russian education system are effective. These features include emphasis on student groups - where students study and do research together and emphasis on working research seminars among others.

The main objective of this paper is to (briefly) describe successful features, with the hope that they may be useful in the American education system as well. Some of these features have already been successfully implemented (with appropriate adjustments) in UTEP's affinity research groups. Refer to, e.g., [1], [2], and [7].

\section{Motivations AND CLARIFICATION}

Why the Russian experience? Two of us have been educated in Russia: Vladik Kreinovich received his Master's degree from the computer-related division of the Mathematics Department of St. Petersburg University and his Ph.D. from the Institute of Mathematics of the Siberian Department of the Russian Academy of Sciences; Olga Kosheleva received her Master's degree from the Novosibirsk University, Russia. Both observed the Russian educational system as students and as teachers, so we are very familiar with different aspects of this system.

This paper is not a comprehensive survey. We omit all the features that we consider bad (and there were many) and concentrate only on the features that can be useful. Our choice of effective features is (inevitably) subjective - mainly based on our own experience and on our collaboration with Prof.
Nesterov (St. Petersburg, Russia). We hope, nevertheless, that in spite of this subjectivity, this paper will be useful.

Our main objective is to attract attention to (not well known) educational techniques - especially since we have tried some of these techniques, and they work well. Readers interested in more details of the aspects of the Russian educational experience emphasized in this paper can study [3], [4], [6], [8], [9], and references therein.

\section{3-TIER SYSTEM OF STUDENTS}

To get admitted into a Russian university, it was necessary to pass entrance exams. Every Department had its own set of entrance exams, usually, very tough, and usually, very specific. A student whose knowledge was not sufficient for a selected department could prepare better and try again the following year.

At first glance, it may sound different from many American state universities, where every student with a valid high school diploma can get admitted, but in reality, the situation is not that different. For example, at the University of Texas at El Paso, every high school graduate can become a student but it does not mean that every high school graduate can become a computer science or engineering major. Every incoming student takes placement tests based on which a few best students are placed directly into the computer science or an engineering program, but most take remedial classes until they successfully attain the needed level of knowledge. In other states, like in Russia, remedial classes are taught outside the university (e.g., at community colleges). Based on the results of the entrance exams, accepted students were divided into 3 tiers.

\section{FULL-Time STUDENTS}

The best students were accepted into a full-time program. These students were usually given stipends that provided (minimal) subsistence, so they did not have to work. This stipend was kept as long as a certain GPA is maintained.

Full-time students from out of town were also usually given a free place in the dorms or a possibility to (cheaply) rent a room through a special university-mediated and university-subsidized placement service. Full-time students were on the fast track, they received their B.Sc. and M.S. degrees in five years. 


\section{WORK-STUDY AND DISTANCE-LEARNING STUDENTS}

Since every full-time student was financially supported, the number of full-time students was limited by the available funding. Students who passed the entrance exams - but not so well as to qualify for this status - became either work-study students (if they live in the same town as the university) or distance-learning students (if they live out of town).

Work-study students worked full time. To accommodate these students, they attended special evening classes. Of course, since work-study students also worked, they could not take as many classes as full-time students, so it took these students somewhat longer to graduate than full-time students.

Out-of-town work-study students became distancelearning students. Throughout the semester, these students received their lecture notes, handouts, and assignments remotely, and they sent their assignments by mail, which were graded and checked. To compensate for the lack of direct contact with professors, at the end of every semester, these students came to town for a month-long on-campus crash course to solidify their knowledge before the finals. These students took even longer to graduate than work-study students.

The best work-study and distance-learning students usually became full-time students; some of the original fulltime students failed, some decided to change their field of study, opening full-time slots. The best work-study and distance-learning students took these slots.

\section{STUdents From All THREe TiERs RecEIVED THE SAME KNOWLEDGE}

It is important to emphasize that the same material was taught to students of all three tiers, and the final exams for all these three tiers of students were given by the same professors at the same level of difficulty. In principle, students from all three tiers gained the same level of knowledge. However, in general, employees preferred full-time students because they received higher grades originally and so they had a reputation of being smarter than students from the other tiers. This preference was an additional incentive for work-study and distance-learning students to study harder so that they would graduate as full-time students.

\section{Clusters}

Until their senior year, full-time students had practically no choice: they had to take the pre-determined sequence of classes (clusters) every semester. This was a very heavy studying load: about 6 hours of classes every weekday and Saturday, with a large amount of homework for each class. After the first three years, the students chose a specialization within their discipline, and this allowed them more freedom in selecting their classes.

The main advantage of clusters was the ability to correlate different courses taken at the same time. For example, when physics and calculus were taken at the same time, both professors could correlate exactly when, say, the notion of a derivative was introduced in math and in physics. As a result, mathematical and physical aspects of this notion were taught simultaneously and helped students relate different areas.

An additional advantage was that when the entire class of students from, say, math or computer science, enters physics or philosophy, there were enough students to organize a special section of this class. The corresponding course was specifically tailored towards students from this very major. This tailoring improved the understanding of the material.

\section{GROUPS}

Most of the classes were taught in two parts: a big lecture for the entire class, and additional (closed) labs for groups of students (usually, 15-20). To accommodate this, all the incoming full-time students were divided into groups of 15-20 students in each.

Students were assigned to the same group for all classes, with a few exceptions such as foreign language, where division is by language and by mastery level, and physical training, where division is by sport and by mastery. Similarly, work-study students were also divided into groups.

\section{How To Divide STUdENTS INTO GROUPS}

Division into groups is very important: students in a group study together and help each other. As a result, much thought was given on how to divide students into groups.

Some students came to the University from a special university-sponsored advanced boarding high school, where they studied together. These students were already accustomed to working together, so they were usually placed into one group. Other students were distributed uniformly, so that each group would contain, e.g., approximately the same proportion of $\mathrm{A}, \mathrm{B}$, and $\mathrm{C}$ students and approximately the same proportion of male and female students. The latter technique promoted heterogeneity.

\section{GROUP ADVISORS}

For each group, three advisors were assigned: two doctoral student advisors and a faculty advisor. Graduate student advisors spent a few hours every week with a group. Their main duty was to teach the group learning skills, to provide advice on how to study, and even how to relax. Everyone benefited from this arrangement: advisees received help and advisors gained pedagogical experience. In addition, they enjoyed being treated like "gurus with infinite wisdom."

Since student time was very strongly regulated, advising was regulated as well. Every doctoral student was required to be an advisor with a (Pass/Fail) grade every semester.

A faculty advisor was usually advising several groups. Once in a while, a faculty advisor met with the group and/or with individual students. The main duty of a faculty advisor was to handle conflicts or emergency situations that required the authority of a professor.

\section{MAIN FUNCTION OF A GROUP: STUDY}

The main function of the group was to study together. Due to the tough initial selection, usually, most of the students had 
the potential and the background to succeed. In practice, however, in each subject, some students were somewhat ahead and some were somewhat behind. Students who lagged behind slowed down others. To avoid this problem, members of the group were supposed to spend some time together and help each other within small study groups of 2-5 students. This arrangement was beneficial to all the students: helpers improved their knowledge; and helpers received help in other subjects as well as other parts of the material.

Special self-study weekly periods were allocated for this mutual help. Group advisors supervised and helped to structure mutual help sessions.

This study was especially important, since in advanced classes, professors rarely followed textbooks. Thus, notes taken by students were extremely important. Although attendance was required (only straight A students received special permission to study on their own and spend the saved time for early entrance into the world of research), occasionally a student would have to skip a class or two. In this case, he or she could always rely on the notes of other students from the small study group.

\section{A GROUP AS AN EXERCISE IN SELF-GOVERNMENT}

In addition to studying, the group served as an exercise in selfgovernment. Students elected several representatives such as a group leader, an academic leader, a political information leader, and a cultural leader.

The variety of positions and yearly re-elections allowed practically all students to practice leadership skills by using their personal skills and preferences. This leadership experience helped those who went towards their Ph.D. to become successful group advisors. Of course, those who had strong leadership skills could run for election in the departmental or university-wide student bodies.

The group had a strong degree of self-government. For example, in general, the rule was "one strike and you're out." One F usually meant out of school. F's did happen because of personal problems, bad luck, laziness, or illness. Whether to give a student a second chance was up to the group. After all, the group worked with the student all semester long and they know the person the best. If they saw that the person really tried, then they usually recommended him or her to stay, and by this recommendation, implicitly agreed to help if needed. On the other hand, if the person was simply not committed, then they usually recommended expulsion because they did not want to waste time on helping a person who does not want to study. The group knew very well that there are work-study students willing to study hard and eager to take a place of an unmotivated student.

Another example of a self-government was to resolve (rare) conflicts between student members - at least give it a first try. If the group could not resolve the conflict, then the higher authority (usually, a faculty advisor) could seek the opinion of the group.

\section{NOT NERDS}

Much effort was made not to let students become nerds. For example, one of the duties of a cultural leader was to organize group parties and participate in the organization of universitywide parties. The university usually gladly allowed the students to use its facilities and dorms. The university also had special agreements with local professional theaters so that students could get affordable discount tickets; these tickets were usually distributed via the cultural leaders. On top of that, the university environment provided opportunities for entertainment such as poetry evenings, the university theater, and other cultural events for which the cultural leaders served as a promotion network.

The main responsibility of a political information leader was not to let students forget that there is a world outside the department. For that, the leader prepared short weekly 5-10 minute oral news reports in which the main idea was not only to inform about the current events, but to get students interested in the news. Usually, one of the humanity classes reserved a few minutes every week for this information. Alternatively, a few minutes were reserved during scheduled study sessions. For this same purpose, political information leaders helped to design and post department-wide newspapertype news digests.

\section{From STUdy TO RESEARCH: 3-TIER SYSTEM OF SEMINARS}

Staring from their freshman year, students were encouraged to attend research seminars. There were three types of seminars.

First, there were formal seminars to present published or publishable results. The main goal of a seminar was to understand the material thoroughly. The main way of achieving this goal was to ask questions. These questions were encouraged by the seminar leader. One of the major tasks of the seminar leader was to ask questions until the point became crystal clear. These seminars benefited both the speakers and the students: presenters improved their papers before submission and students learned state-of-the-art research results as well as the difficult art of understanding and asking questions.

What the students did not learn from these seminars was what was needed to be done to get the results being reported. This process was learned through seminars of a different type: working seminars. In working seminars, a group of researchers regularly got together to work on open problems. At working seminars, students started with presenting papers assigned by the seminar leader and, eventually, progressed to presenting their own ideas and results. Starting from the junior year, a student was required to attend a seminar every semester, to make a presentation, and to get a credit for it from the seminar leader. After attending a few seminars, a student was required to choose an area for his or her Master's thesis.

Finally, there were regularly scheduled interdisciplinary seminars in which people from different disciplines presented their results. These seminars provided a unique opportunity to learn about research in other disciplines and to progress in 
interdisciplinary research. Many important ideas originated on these seminars.

\section{FROM STUDY GROUPS TO RESEARCH GROUPS}

At the beginning of their senior year, students selected a subdiscipline within their major, a sub-discipline which would be their main research direction. As a result, students rearranged themselves into new groups that were research-oriented. These students already knew each other from attending the same working seminars.

In these new groups, students not only studied together, but they also helped each other do research, with a seminar leader taking the role of a faculty group advisor. Students with more experience in this area played the role of student advisors.

\section{REQUIRED DEPARTMENT-APPROVED INTERNSHIPS}

One semester internship is required. A work plan has to be approved by the department to ensure that students actually would learn something new. There were two types of internships: paid internships at companies and (largely unpaid) highly competitive internships at top research centers. Students who were selected for the unpaid internships still received their stipends from the University.

Real-life experience helped the students understand the real-life problems, and it helped motivate them in studying different subjects - by showing that these subjects are of actual practical use. Besides, interning for a company improved the student's chances of getting hired by this company.

\section{ADDITIONAL INCOME FOR STUDENTS}

For full-time students, their main income was their stipend. Paid internships provided additional income. One more source of income was summer jobs. There was an incentive for companies to hire students for summer jobs because they received substantial tax exemptions.

Companies interested in the department's graduates pay money to the university (via the state budget). This money covers part of the university budget and the students' stipends. The main benefit to the company was that the company was guaranteed to get a certain amount of graduates. Specifically, a student was contractually obligated to work for a universityassigned company for a certain amount of time (usually 3 years); however, the company was not obliged to hire any graduate. If a graduate could not find a job, the university was required to continue training and paying the person a stipend until he or she found a job.

Of course, this created problems because this system required long-term planning and commitments. The solution to these problems was to institute periodic flexible changes in degree plans when market demanded changes. For example, one year before one of us (V.K.) started studying at the Math Department, the University realized that there were not enough jobs for pure mathematicians, so all the math students received a minor in computer science.
These arrangements are not that easy to emulate. We are currently trying our best to get in contacts with different companies, and we have good relationships with many of them.

\section{COMPARISON OF THE RUSSIAN EXPERIENCE WITH THE AFFINITY RESEARCH GROUP MODEL}

The Affinity Research Group (ARG) model [1], [2], and [7] was developed at the University of Texas at El Paso to involve undergraduate and graduate students in research and technical activities outside of the classroom. The model integrates best practices from industry, research, and education. While different in many ways from the Russian model, there are many experiences from that model that are incorporated in ARG. First, we provide a brief overview of ARG. Next we describe the similarities and differences.

An ARG is a team composed of faculty mentors and undergraduate and graduate students. Students often have varying levels of expertise, capabilities, interests, and skills as well as a variety of educational and cultural backgrounds. Through ARG, students develop cognitive and interpersonal skills in a highly structured and deliberate manner, rather than in an ad hoc way. ARG provides faculty with guidelines for facilitating efforts in organizing, operating, and maintaining effective research groups that focus not only on the research itself, but also on the conscious development of students within a cooperative environment. An important feature of affinity groups is that they are built around the cooperative team paradigm [10] and [11]. The key to successfully using the cooperative team paradigm is to incorporate the basic elements, which are:

- building positive interdependence within the group,

- supporting member's progress and involvement through promotive interaction and constructive critique,

- developing a strong individual by ensuring that each student is responsible for his or her deliverables, and

- teaching and practicing team skills, and reviewing on a regular basis how well the group is functioning and achieving its goals.

While the Russian model recruits the top students, the ARG model has been highly effective at developing students who are competent, but who may not have chosen to participate in research or extracurricular activities due to lack of confidence. The model was originally devised to increase the number of students, particularly those from underrepresented groups, who succeed in Science, Technology, Engineering, and Mathematics (STEM) programs and continue to graduate school. Through evaluation and assessment, we found that an ARG experience instills in many of the students the desire to continue their education and development. The ARG concept incorporates mechanisms that address persistence, a critical characteristic for academic success [12] and [13]. Ultimately, the students involved in ARG become some of the best students in the department. Although it could be argued that ARG has a 3-tiered system (in this case, undergraduate, Master's, and Ph.D. students), the group integrates all students into a single group.

October 28 - 31, 2006, San Diego, CA 
Similar to groups in the Russian model, an ARG typically has 15-20 students that come together to contribute to a specific research effort. The faculty mentors strive to create groups that are distributed uniformly with respect to ethnicity, gender, and academic classification. The ARG philosophy advocates active recruitment of competent, diverse students, especially those who show potential, but may lack confidence to seek a research position. Recruitment of students with diverse abilities and backgrounds infuses different perspectives into research activities, increases the number of students involved in research, and increases the number of students who continue with their education.

Unlike the Russian model, ARGs do not advocate elected student leaders. While traditional research groups are hierarchical in structure, i.e., a top-down model in which the layers represent different orders of expertise and authority, ARGs incorporate an integral model, i.e., one in which faculty mentors and students work as peers. Because of the cooperative model, students take on the role of advisors and mentors although these are not elected positions. Our experience shows that students in ARGs form clusters and self-study sessions in which members help each learn the material in the classroom. The notion of having representatives in the group serve as political information and cultural leaders is appealing. In ARGs, a student typically takes on the role of organizing social events in a more informal manner than in the Russian model. All ARG members are asked to become engaged in at least one outreach activity a year, which allows students to give back to the community as well as build social awareness.

Although there are some students who volunteer to be part of an ARG, most students are funded through research grants. Students, especially undergraduate students, are encouraged to apply for internships during the summer for the same reasons as described in the Russian model.

The areas in which there is the most overlap with the Russian and ARG models are in the different seminars that are scheduled in the groups. As with the Russian model, the ARG model schedules seminars in which published or publishable results are presented. Because the ARG model focuses on developing technical and research skills, special attention is given to developing higher-level thinking skills, e.g., asking good questions and seeking understanding. The other seminar that is used is the working seminar in which the group brainstorms on research questions and work toward solving problems posed by a faculty mentor or student.

In addition to the seminars, ARG uses activities that work on honing oral and written communication skills. This may entail constructive critique by the audience in the case of a presentation, or review and constructive critique of a written document. Another example activity is one in which the faculty mentor and two or more students work on the revision of a research paper. This provides an opportunity to teach concepts related to writing technical papers.

ARG regular meetings are scheduled to report progress, promote the refinement of short-term goals and solve problems encountered by students. Regular meetings also are used to build positive interdependence, practice promotive interaction, structure individual accountability, practice team, communication skills, and develop domain expertise. The format varies depending on the needs of the group, whether it is developing cognitive or interpersonal skills or revising research goals, tasks, and methods. A concern of having undergraduate and master's students on a research project is that they may not be active in the project for as long as doctoral students. To address the risk of rapid student turnover, students work cooperatively on similar tasks as pairs or triads.

\section{EVALUATION OF ARG}

Evaluation of the ARG model [2] and [14] was completed by an independent evaluation team that used a multi-method approach: surveys, interviews, and participant observation. Based on the nature and context of the project, evaluation focused on the model's impact on students. The evaluation activities and results were designed to help ARG faculty mentors improve, articulate, and assess the impact and effectiveness of the model.

The demographics of affinity groups' membership for 1995-2000 were as follows: 175 total members; $42 \%$ graduate student members (7\% Ph.D. students); 58\% undergraduate student members; $78 \%$ members from underrepresented groups (22\% female members); $35 \%$ members graduated with BS; $22 \%$ members graduated with MS; two members graduated with a Ph.D.; 30\% of the undergraduates continued to graduate school. In addition, the groups had over 150 research publications; over 100 research publications (journal and conferences) with students as co-authors; 23 publications and talks on the Affinity model; 66 student presentations at student conferences; and 25 student awards and recognition.

Faculty members continue to use the ARG model in the department. Through NSF funding, the model is being disseminated to other institutions and evaluated to determine the effect of the model on programs with different demographics.

\section{OTHER APPLICATIONS OF THE RUSSIAN EXPERIENCE}

Faculty members from UTEP's Computer Science program are also using several innovative teaching techniques partly motivated by the Russian experience. We actively use student groups in which students study together and help each other. In addition, we use clusters of inter-related courses instead of more traditional independent courses. In some courses, peer leaders use recitation sessions (semi-lectures, semi-labs) taught for small groups of 10-15 students in addition to standard lectures.

We have regular seminars in which students are encouraged to referee papers and to present their own results; attending a seminar is now a requirement for incoming Computer Science students and their report of what they learned on two seminars per semester is a part of their grade.

All these ideas have led to good results, in terms of improved educational results of the participating students, larger interest in research, and (last but not the least) improved

October 28 - 31, 2006, San Diego, CA 
Session T1A

student interest in Computer Science and improved selfesteem.

\section{ACKNOWLEDGMENT}

This work was supported in part by NASA under cooperative agreement NCC5-209, NSF grants EAR-0225670, DUE0443061, CNS-0540592, and DMS-0532645, Army Research Lab grant DATM-05-02-C-0046, Star Award from the University of Texas System, and Texas Department of Transportation grant No. 0-5453.

This paper is partially based on the talks that we presented one of at the regional ACM meeting in Pinos Altos, New Mexico, and at the 2006 International SUN Conference on Teaching and Learning (El Paso, Texas, March 2006) [5]; the authors are thankful to all the participants of these meetings for valuable comments.

\section{REFERENCES}

[1] Bernat, A., Teller, P., Gates, A., Delgado, N., and Kubo Della-Piana, C., "Structuring the Student Research Experience," ACM SIGCSE Education, Vol. 32, No. 3, 2000), pp. 17-20.

[2] Gates, A.Q., Teller, P.J., Bernat, A., Delgado, N.., and Kubo DellaPiana, C., "'Expanding Participation in Undergraduate Research Using the Affinity Group Model," Journal of Engineering Education, Vol. 88, No. 4, 1999, pp. 409-414.

[3] Idlis, G. M., Ladyzhenskaya, O. A. (eds.), A. D. Alexandrov, Nauka Publ., Moscow, 2002 (in Russian).
[4] Khalatnikov, I. M. (ed.), Landau, the physicist and the man: recollections of L.D. Landau, Pergamon Press, Oxford, New York, 1989.

[5] Kreinovich, V., Gates, A., and Kosheleva, O., "Helping Students to Become Researchers: What We Can Gain from Russian Experience", Abstracts of the 2006 International SUN Conference on Teaching and Learning, El Paso, Texas, March 3-4, 2006, pp. 17-18.

[6] Mayer, M. E., "Reminiscences of the Landau Seminar 1957-58", In: Gotsman, E., Ne'eman, Y., and Voronel, A. Eds, Frontiers of Physics, Pergamon Press, 1990.

[7] Teller, P. Gates, A. Q., "Using the Affinity Research Group Model to Involve Undergraduate Students in Computer Science," Journal of Engineering Education, October 2001, pp. 549-555.

[8] The US Education Advising Center in Moscow, Systems of Russian Education, http://www.useic.ru/russian_education/

[9] Vershik, A. M., "Summa" for the Free Thought, Zvezda Publ., St. Petersburg, 2002 (in Russian).

[10] Johnson, D., R. Johnson, and K. Smith, Active Learning: Cooperation in the College Classroom, Interaction Book Company: Edina, MN, 1991.

[11] Johnson, D., R. Johnson, and E. Johnson Holubec, Advanced Cooperative Learning, Interaction Book Company, Edina, MN, 1992.

[12] Tinto, V., Russo, P, \& Kadel, S., “Constructing Educational Communities: Increasing Retention in Challenging Circumstances." Community College Journal, 64, 1994, 26-30.

[13] Rodriguez, C., "Keeping Minority Undergraduates in Science and Engineering," $19^{\text {th }}$ Annual conference of the Association for the Study of Higher Education, Tucson, AZ, November 1994.

[14] Della Piana, C. and A. Bernat, "Evaluating the Undergraduate Research Experience in Computer Science: Developing a Framework for Gathering Information about Effectiveness and Impact,” Proceedings $29^{\text {th }}$ ASEE/IEEE Frontiers in Education, November 1999. 